\title{
Controlling Effects of Residual Deformation on Pore Pressure: A Loess Soil Case
}

\author{
Kun Liu $\mathbb{D}^{1,2}$ Lanmin Wang ${ }^{10},{ }^{2}$ Wentong Tian, ${ }^{2}$ Zhenming Wang, ${ }^{3} \mathrm{Na} \mathrm{Li}^{2}{ }^{2}$ Yu Sun, \\ and Junjie Sun $\mathbb{D D}^{2,5}$ \\ ${ }^{1}$ College of Civil Engineering and Mechanics, Lanzhou University, Lanzhou, Gansu 730000, China \\ ${ }^{2}$ Key Laboratory of Loess Earthquake Engineering, Lanzhou Institute of Seismology, China Earthquake Administration, Lanzhou, \\ Gansu 730000, China \\ ${ }^{3}$ Kentucky Geological Survey, University of Kentucky, Lexington, KY 40506, USA \\ ${ }^{4}$ Earthquake Administration of Shaanxi Province, Xi'an, Shaanxi 710068, China \\ ${ }^{5}$ College of Civil Engineering and Architecture, Wenzhou University, Wenzhou, Zhejiang 325035, China
}

Correspondence should be addressed to Junjie Sun; sunnjunj@163.com

Received 30 June 2019; Accepted 18 November 2019; Published 18 December 2019

Academic Editor: Nerio Tullini

Copyright ( $\odot 2019$ Kun Liu et al. This is an open access article distributed under the Creative Commons Attribution License, which permits unrestricted use, distribution, and reproduction in any medium, provided the original work is properly cited.

What the role of each phase medium plays and how their interactions do work should be essential problems to understand dynamic behaviours of soils. In order to disclose interactions between solid, water, and air phases of soils, we applied loess samples to analyse controlling effects of residual deformation on pore pressure based on three kinds of laboratory tests. We obtained the similarity and difference of mechanical behaviors of soil samples under different water contents and loading. Both process and cause of pore air/water pressures are independent of initial stress conditions or loadings. However, absolute values of pore water pressure depend on the confining pressure, whereas the pore air pressure is contrary. The uniformity of responding process and cause of pore pressure depend upon the interaction mechanism between solid particles and air/water media, but the different absolute values depend upon the permeability and compressibility of air/water.

\section{Introduction}

Loess is a kind of uniform, cohesive, and wind-blown sediment within Quaternary period. In China, the loess area reaches $640,000 \mathrm{~km}^{2}$, in which $440,000 \mathrm{~km}^{2}$ distribute within Loess Plateau. Generally, $Q_{3}$ loess has much higher porosity and weaker cohesion than soils of $Q_{1}$ and $Q_{2}$ loess. Under some conditions such as rainfall and earthquake, $Q_{3}$ loess could cause geotechnical hazards, differing from relative stable soils of $Q_{1}$ and $Q_{2}$ loess. In case of saturation, the bond between particles is weakened and the depositing surface may settle. This topic of loess collapsibility is mainly concerned during the early stage [1-4]. On the other hand, if the dynamic loading is large enough, the saturated $Q_{3}$ loess could suffer liquefaction, as well as seismic subsidence at unsaturated conditions. Figure 1 shows essential features of loess thickness and seismicity and historical sites of loess geological hazards (blue stars) in Loess Plateau. Those dots located in high-risk seismicity may have relations with strong ground motion, whereas other ones within low-risk areas should be caused by rainfall.

Before there have been clear concepts such as seismic subsidence and residual deformation of soils, in 1960s, Seed et al. have applied laboratory tests to study the soil topic of seismic subsidence [5]. Then, in 1970s, Lee investigated the soil residual strain by means of dynamic triaxial tests with cyclic loadings [6]. The seismic subsidence of loess was considered in the 1980s, and the study of loess liquefaction began in 1990s. The research methods often draw lessons from dynamic topics of other soils, e.g., liquefaction evaluation of saturated sand proposed by Seed and Idriss [7]. Because of having a natural structure in field, the undisturbed samples of loess soils are not easy to prepare, especially the large size model for the shaking table test. These factors lead to the fact that the liquefaction features of loess have not been studied clearly. For example, compared to sand liquefaction, loess liquefaction is just regarded as a 


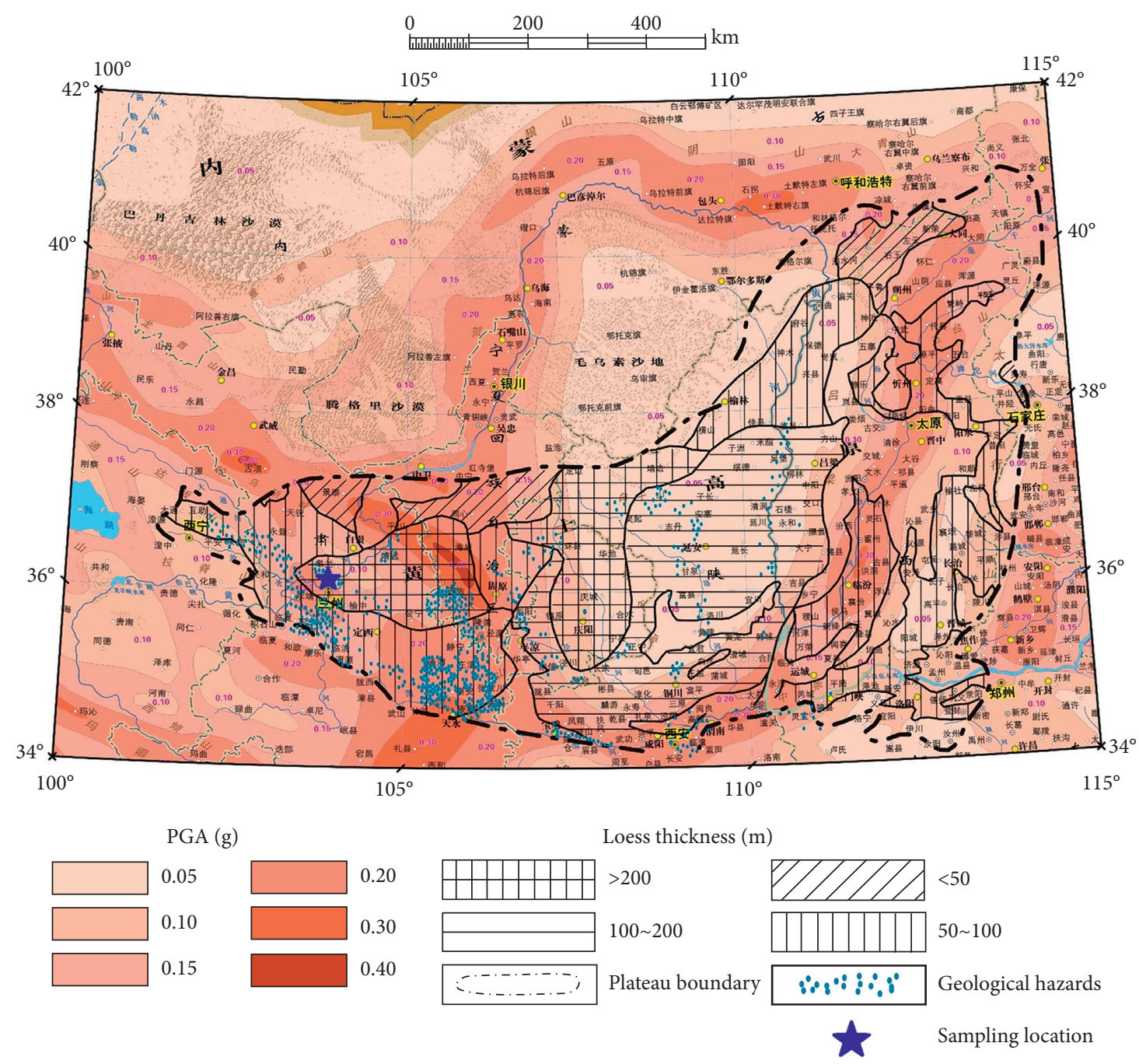

FIgURE 1: Loess thickness, seismicity risk, and historical geological hazard sites.

cyclic shear failure or a nonreal phenomenon. Wang and Sun applied the shaking table test to reveal the mechanical features of loess liquefaction by large size disturbed samples [8]. Their results showed the saturation level controls loess liquefaction process, and the loess liquefaction could reach a real liquefaction if its saturation level is high enough. For having much more finer particles than sand, the saturation level of real liquefaction should not reach $100 \%$.

Unsaturated soil is a kind of triphase media with solid, water, and air, whereas saturated soil has two phases of solid and water. Because shear stress cannot propagate through water and air, the soil particles may be the first-response media under dynamic loadings. Although most research works generally separate residual deformation from pore pressure, some laboratory data show residual deformation of soil has relation with pore pressure during their common developing processes under cyclic loadings. Chang provided a method to describe the increment relation between pore pressure and residual deformation [9]. Based on dynamic triaxial tests with cyclic loadings, Kimura et al. showed that the relation between pore pressure and residual deformation should be linear with vertical strain less than $2 \%$; and after further development of vertical strain, the increase of pore pressure tends to become gentle [10]. Then, a similar laboratory result was obtained by Yamaguchi et al. [11]. Shi analysed the corresponding relation between pore pressure and residual strain by means of dynamic tests with sinusoidal loadings [12]. Unfortunately, there is no a clear proof to show whether the residual deformation is the direct reason to make pore pressure develop, especially for the different cases of natural loess under the saturated and unsaturated conditions.

For a certain kind of soil, its mechanical behaviour mainly differs from water contents and loading types. During this process, what the roles of each phase medium of solid, water, and air play and how those roles and their interactions work are still not clear, especially for those dynamic cases. This paper tries to understand the similar and the different points of residual deformation controlling pore air and water pressures based on the loess testing case in laboratory. The direct purpose is to disclose the micromechanism or real contributions of each phase medium during the loading response of soils by means of analysing the relationship between residual deformation and pore pressure of loess under external loadings. 


\section{Methods}

2.1. Samples and Laboratory Tests. The undisturbed loess samples are taken from a $Q_{3}$ loess field located in Jiuzhou Development Zone of Lanzhou city, Gansu province of China. Figure 2 provides graduation features of those loess samples, and Table 1 lists their physical properties.

In order to understand the relation of residual deformation and pore pressure, we apply three kinds of laboratory tests, i.e., static/dynamic triaxial test, soil-water characteristic curve test, and permeability test of water (see Figure 3). These tests are completed in the Key Laboratory of Loess Earthquake Engineering, China Earthquake Administration, Gansu province.

The static/dynamic triaxial tests are completed by the TYD-20 instrument, obtaining time-history data of vertical/ bulk residual strain, pore air/water pressure of saturated/ unsaturated loess, and basic physical parameters of the samples. The loading of static triaxial test is controlled by equal strain increment (starting value is axial consolidation stress), and the load process is controlled by equal strain increment $(0.9 \mathrm{~mm} / \mathrm{min})$. The loading of dynamic triaxial test is equivalent cyclic load $(1 \mathrm{~Hz}$ frequency, the load duration reflects by dynamic stress load times). The load strength is selected by burial depth of samples [13]. The whole testing process maintains no drainage and no exhaust. The physical parameters were tested according to the relevant laboratory codes.

In the static/dynamic triaxial test, the samples need to be consolidated as the condition of axial/confining pressure in Table 1, and then those samples are loaded corresponding to the static/dynamic load. Six static triaxial test samples contain three unsaturated samples (US) and three saturated samples (SS); four dynamic triaxial test samples contain two unsaturated samples (UD) and two saturated samples (SD). The consolidation standards adopted are based on the current provisions of geotechnical test procedures. The soil sample deformation is less than $0.5 \%$ in 5 minutes. The consolidation time of unsaturated loess is about 20 minutes. The saturated loess needs 1-2 hours. The method of degassing water seepage water cycle can make the samples saturated.

The soil-water characteristic curve is obtained by the Frelund soil-water characteristic instrument, analysing the water phase migration in the saturated loess. The water permeability test is applied to test the permeability of the natural loess by using the ST55 modified permeameter with variable water head. The testing process followed the Specification of Soil Test of China.

It is difficult to directly measure the soil bulk residual strain. The samples' bulk residual strain in the triaxial test is shown by the volume change of samples. During the testing process, the control system has to flood water in real time maintaining the constant pressure. The change of samples' volume determines the control value of water flooding. The instrument TYD-20 can get the water flooding change value of the confining control system. The bulk modulus of water is $2.2 \times 10^{6} \mathrm{kPa}$, which is used to represent the bulk residual strain of samples, considering the water incompressibility and the correlation between volume changes of samples and water flooding controlled by confining pressure.

2.2. Analysis Method of Laboratory Data. In order to reduce the uncertainty due to properties of soil samples, normalization processing is applied to all recorded data (record data/the maximum record data; see Table 2). The original shear strength is calculated by the Mohr-Coulomb strength criteria depending on the test data of cohesion force and internal friction angle with natural and saturated water contents and the consolidation stress conditions in Table 1. The referent values of cohesion and internal friction angle of samples are obtained by the UU triaxial test, which are around $31 \mathrm{kPa}$ and $28^{\circ}$ of samples with initial water content and $3 \mathrm{kPa}$ and $7^{\circ}$ of saturated samples. Figure 4 shows the testing results of vertical residual strain (VRS), bulk residual strain, and void water/air pressure (VWP/VAP). For the normalization data, 1.0 figures the maximum value and $0 \sim 1.0$ shows the middle features of the response process.

Table 3 shows the test data of loess samples' soil-water characteristic curve, and Table 4 shows the test data of loess samples' permeability. In the soil-water characteristics curve test, the matrix suction is equal to the internal air pressure of soil, and the air pressure increased with the decrease in soilwater content from the data in Table 3. Compared with the natural water content in Table 1 , the matrix suction of unsaturated loess is greater than $2 \mathrm{MPa}$, but the test stress is less than $2 \mathrm{MPa}$ similar to the stress in earthquakes. The water phase of unsaturated loess in the static/dynamic triaxial test would not occur due to migration and compression (under normal conditions, the pressure increased per $100 \mathrm{kPa}$ and the volume of water compression rate was $0.005 \%)$. At the same time, the water phase is not connected, and then the air phase is the only phase having contributed to the pore pressure in the unsaturated loess. The water phase is the contribution phase to the pore pressure in the saturated loess.

Table 4 shows that the water permeability of natural loess samples which have similar physical parameters is lower than the air permeability around 3 orders of magnitudes. Under the static/dynamic load, the stress response parameter of unsaturated loess is pore air pressure, and the stress response parameter of saturated loess is the pore water pressure.

\section{Results}

3.1. Different Correlations of External Loading, Residual Deformation, and Pore Pressure. As shown in Table 5 and Figure 5, three kinds of correlations between external loading, residual deformation, and pore pressure differ from loading stages. This may have relation with the complexity of soil stress response under external loadings. During different loading stages, the two kinds of correlation coefficients between external loading and residual deformation or residual deformation and pore pressure are greater than the 


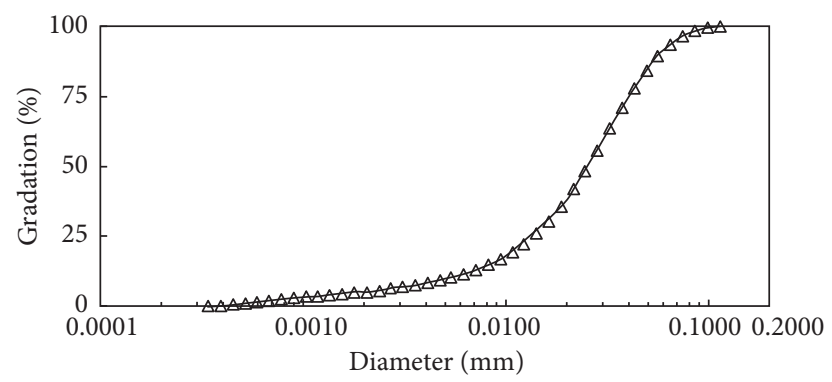

FIGURE 2: Granular analysis of loess samples.

TABLE 1: Physical property of loess samples and loading conditions of static/dynamic triaxial tests.

\begin{tabular}{|c|c|c|c|c|c|c|c|c|}
\hline \multirow[t]{2}{*}{ Sample number } & \multirow[t]{2}{*}{ Natural water content (\%) } & \multirow[t]{2}{*}{ Dry density $\left(\mathrm{g} \cdot \mathrm{cm}^{-3}\right)$} & \multirow[t]{2}{*}{ Void ratio } & \multirow[t]{2}{*}{ Saturation (\%) } & \multicolumn{3}{|c|}{$\begin{array}{l}\text { Load stress } \\
(\mathrm{kPa})\end{array}$} & \multirow[t]{2}{*}{ Triaxial test } \\
\hline & & & & & $\sigma 1$ & $\sigma 3$ & $\sigma \mathrm{d}$ & \\
\hline 1 & 6.5 & 1.34 & 1.02 & 17.2 & 50 & 50 & - & \multirow{6}{*}{ Static loading } \\
\hline 2 & 6.7 & 1.35 & 1.01 & 18.0 & 150 & 150 & - & \\
\hline 3 & 8.2 & 1.36 & 0.99 & 22.4 & 150 & 150 & - & \\
\hline 4 & 6.5 & 1.35 & 1.01 & 83.9 & 50 & 50 & - & \\
\hline 5 & 7.1 & 1.35 & 1.01 & 81.0 & 100 & 100 & - & \\
\hline 6 & 7.3 & 1.34 & 1.02 & 92.7 & 150 & 150 & - & \\
\hline \multirow{3}{*}{7} & & & & & & & 10 & \multirow{6}{*}{ Dynamic loading } \\
\hline & 7.1 & 1.34 & 1.02 & 82.8 & 100 & 90 & 20 & \\
\hline & & & & & & & 30 & \\
\hline 8 & 7.8 & 1.35 & 1.01 & 85.6 & 100 & 90 & 25 & \\
\hline 9 & 8.0 & 1.35 & 1.01 & 21.5 & 100 & 60 & $\begin{array}{c}50 \\
80 \\
100\end{array}$ & \\
\hline 10 & 8.1 & 1.35 & 1.01 & 21.8 & 100 & 90 & $\begin{array}{l}50 \\
80 \\
\end{array}$ & \\
\hline
\end{tabular}

correlation between external loading and pore pressure. The result could reveal that the relation between residual deformation and pore pressure is much closer than external loading and pore pressure. This may mean the solid particle structure is the first response medium under external loadings, and it transfers the static/dynamic stress to the two phases of water and air filled in the solid particle structure. Figure 5(b) shows that the correlations between residual deformation and pore pressure are relatively stable, obviously differing from the unstable features between external loading and residual deformation or pore pressure and external loading.

The correlation between residual deformation and pore pressure could disclose three facts. The first is solid particle structure of soil transfers the external loading causing the development of residual deformation and pore pressure. The second is residual deformation has a natural relation with pore pressure. Third, during different loading stages the stress origin of pore water and air pressure should be the same, which means the difference between pore water and air pressure is just due to the distinctions of their physical properties such as permeability and compressibility (see Table 3).

It could reveal the real relationship between residual deformation and pore pressure to analyse the correlation of the laboratory data such as external loading, residual deformation, and pore pressure. Figure 5 shows that developing processes of residual deformation and pore pressure are similar with the increase of static/dynamic loadings. During the laboratory tests, the deformation sensor records the variation of solid particle structure, whereas the pore pressure sensor obtains the information of two phases of water and air filled in the pore of loess soil. Table 5 provides the correlation coefficients between external loading and residual deformation, external loading and pore pressure, and residual deformation and external loading. The greater absolute value of correlation shows the stronger relation between two parameters; the positive and negative values are, respectively, the feature of positive and negative correlations.

3.2. Identical Developing Processes of Pore Water and Air Pressures. Applying the same normalization method, Figure 6 shows the response processes of pore pressure and bulk residual strain of 10 samples, with the data number of 2376. The goodness of fit between pore pressure and bulk residual strain is near to 1 . Because large data could eliminate the uncertainty of pore air/water pressure response time-history caused by the difference of load mode and water-air phase medium, the result of Figure 6 shows the pore air pressure and pore water pressure have no substantial differences. This 


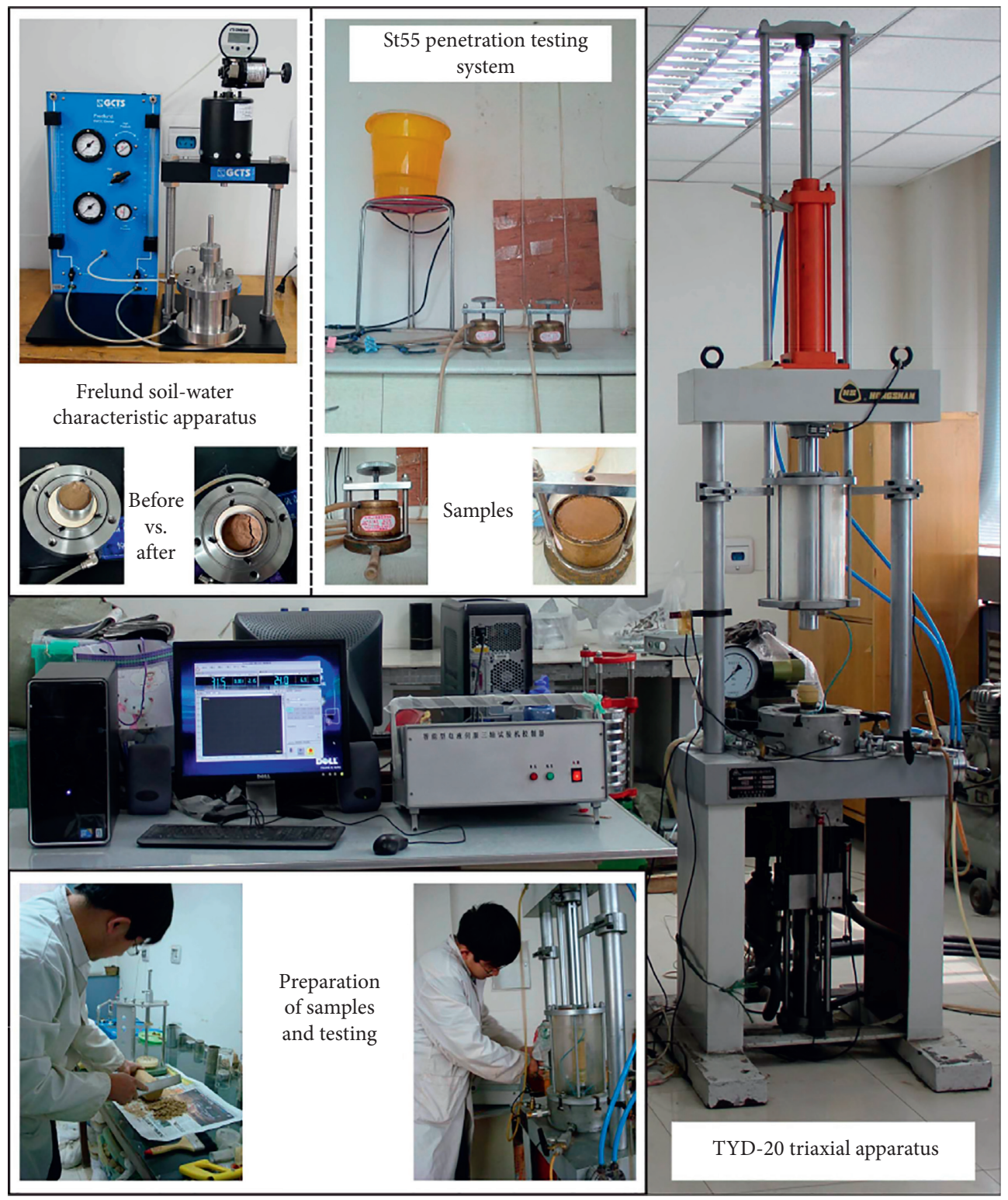

FIgURE 3: Three kinds of laboratory tests and instruments.

reveals the identical developing processes of pore water and air pressures.

The development of water/air pressure must result in the fact that water/air phase medium is compressed by external load. Assuming an ideal state that there is no water and air in the pore of soil, the residual deformation of soil under external loadings cannot generate pore pressure. If the soil pore is filled with water or air and the external load is small enough, when the soil suffers an elastic deformation, water or air in the pore will be compressed by solid phase medium and the water/air pressure may be increased. If the load is turned down, the soil elastic deformation is recovered and the water/air pressure will not exist because the properties of soil do not change, so the potential energy characteristics of water/air phase medium will recover to the original state.

The above theoretical analysis based on the test data can be the evidence to determine the causality between the residual deformation and pore water pressure. The pore pressure and bulk residual strain produced from the process of the soil loading deformation have relatively direct control relationship, and this conclusion is the key to understanding the interaction and correlation process between pore air/ water pressure and external load. The response process consistency of pore air pressure and pore water pressure has been verified. Under the external load the solid phase medium must response foremost and produce residual deformation. Pore air/water pressure was caused by the difference permeability and compressibility of water and air phase medium. And then the residual deformation controls the change of pore air/water pressure. It means that the natural loess residual deformation and pore pressure have causal association which is produced by the cause of solid phase deformation and the results of water/air phase pore pressure change. The change properties of pore pressure 
TABLE 2: The maximum values of corresponding testing data in laboratory for the normalization.

\begin{tabular}{|c|c|c|c|c|c|c|c|}
\hline \multirow[t]{2}{*}{ Sample number } & \multirow[t]{2}{*}{ Shear stress $(\mathrm{kPa})$} & \multirow[t]{2}{*}{ Initial shear strength $(\mathrm{kPa})$} & \multirow[t]{2}{*}{ Effective buried pressure $(\mathrm{kPa})$} & \multicolumn{2}{|c|}{ Strain $(\%)$} & \multicolumn{2}{|c|}{$\begin{array}{c}\text { Excess pore } \\
\text { pressure } \\
(\mathrm{kPa})\end{array}$} \\
\hline & & & & Vertical & Bulk & Air & Water \\
\hline 1 & 101.0 & 58.0 & 52.5 & 19.68 & 0.73 & 1.5 & - \\
\hline 2 & 235.0 & 111.0 & 148.0 & 19.52 & 2.19 & 4.3 & - \\
\hline 3 & 196.2 & 111.0 & 140.8 & 19.36 & 3.00 & 7.3 & - \\
\hline 4 & 10.5 & 9.2 & 34.5 & 17.95 & 1.86 & - & 26.6 \\
\hline 5 & 17.7 & 15.4 & 53.9 & 19.03 & 1.78 & - & 38.9 \\
\hline \multirow[t]{2}{*}{6} & 23.5 & 21.5 & 83.4 & 16.78 & 1.94 & - & 63.8 \\
\hline & 8.3 & & & 0.28 & 0.24 & - & 4.2 \\
\hline \multirow[t]{2}{*}{7} & 9.8 & 14.8 & 46.8 & 2.78 & 0.93 & - & 20.4 \\
\hline & 10.0 & & & 16.97 & 1.23 & - & 28.6 \\
\hline \multirow[t]{2}{*}{8} & 10.9 & 14.7 & 47.8 & 11.14 & 1.16 & - & 28.8 \\
\hline & 49.5 & & & 0.19 & 0.08 & 0.17 & - \\
\hline \multirow[t]{2}{*}{9} & 67.5 & 74.2 & 96.3 & 0.44 & 0.16 & 0.41 & - \\
\hline & 79.9 & & & 0.76 & 0.49 & 2.24 & - \\
\hline \multirow{2}{*}{10} & 33.8 & 822 & 995 & 0.23 & 0.73 & 1.35 & - \\
\hline & 51.3 & 02.2 & 99.5 & 0.44 & 1.70 & 3.69 & - \\
\hline
\end{tabular}
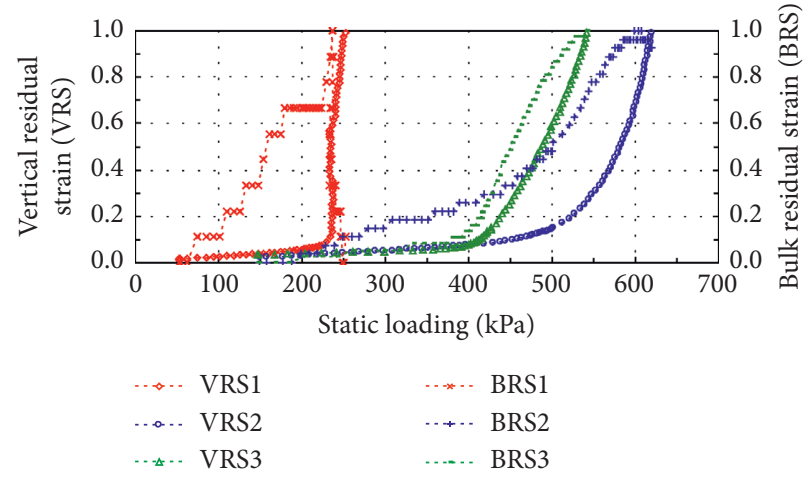

(a)

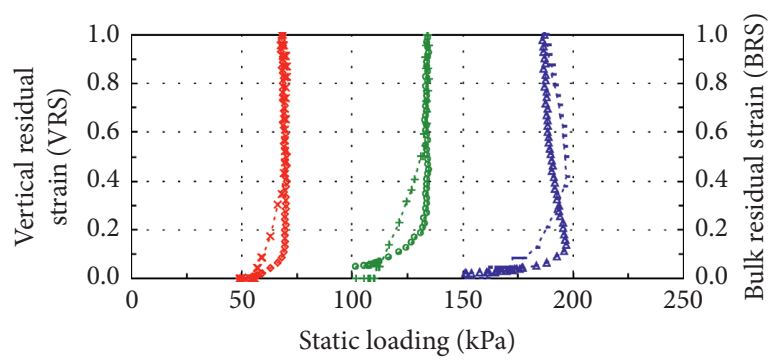

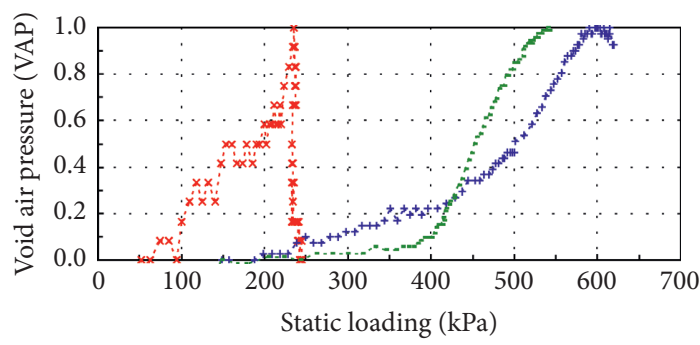

*.. VAP1

$\ldots+\cdots$ VAP2

..... VAP3

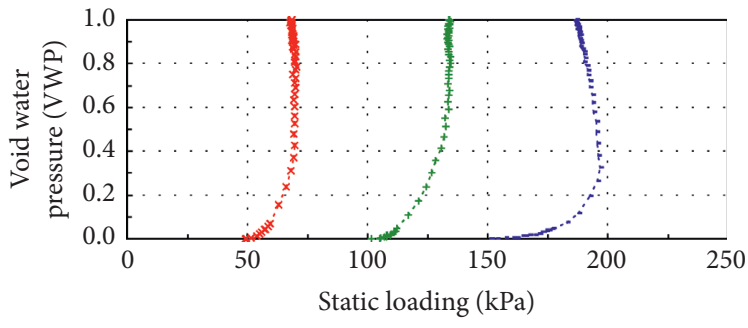

*.. VWP4

... VWP5

... VWP6

(c)

Figure 4: Continued. (d) 


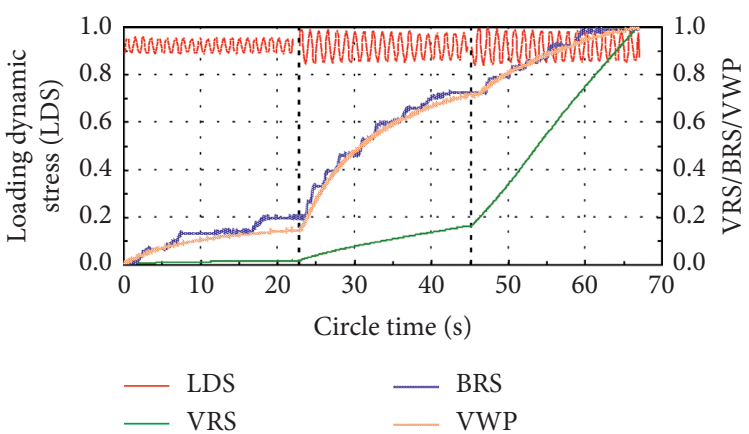

(e)

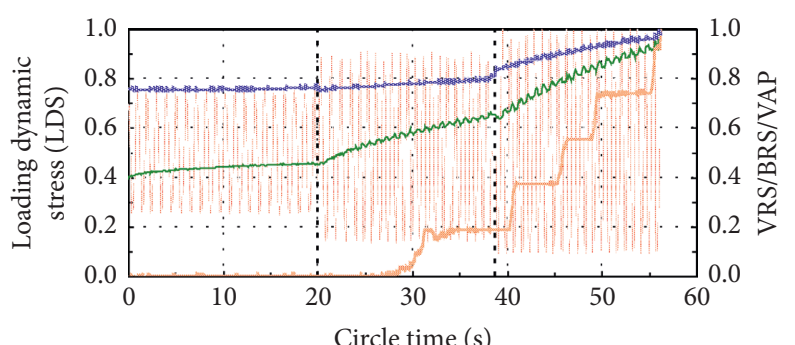

LDS

- BRS
- VRS

VAP

(g)

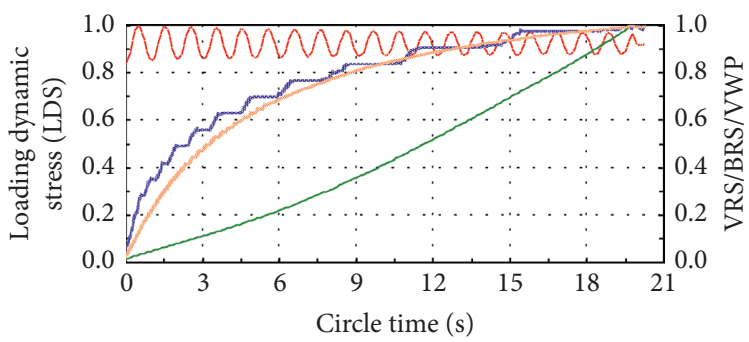

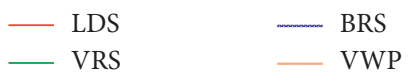

(f)
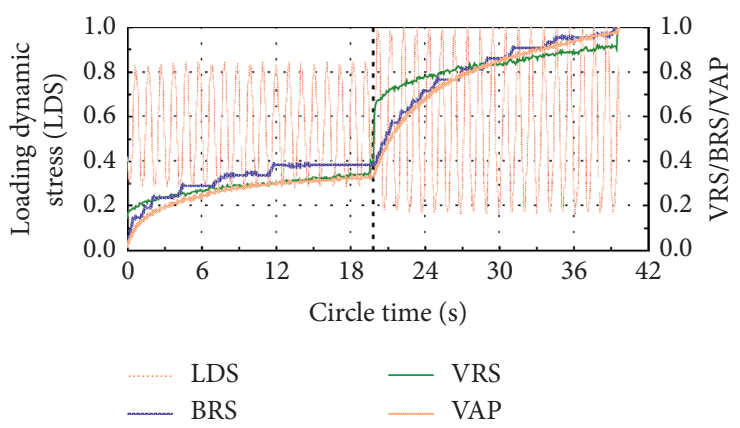

(h)

Figure 4: Response process of natural loess under static/dynamic loadings (normalized by the maximum value of testing data). (a) Samples 1-3 (US). (b) Samples 1-3 (US). (c) Samples 4-6 (SS). (d) Samples 4-6 (SS). (e) Sample 7 (SD). (f) Sample 8 (SD). (g) Sample 9 (UD). (h) Sample 10 (UD).

TABLE 3: The soil-water characteristic curve test data of the loess samples.

\begin{tabular}{lcc}
\hline Suction (air pressure) $(\mathrm{kPa})$ & Water content $(\%)$ & Saturation $(\%)$ \\
\hline 2 & 39.9 & 95.0 \\
4 & 38.4 & 91.5 \\
10 & 34.9 & 83.1 \\
20 & 31.7 & 75.6 \\
40 & 29.1 & 69.3 \\
70 & 25.2 & 59.9 \\
100 & 23.1 & 54.9 \\
200 & 20.8 & 49.6 \\
500 & 16.7 & 39.7 \\
1000 & 13.6 & 32.3 \\
2000 & 10.5 & 24.9 \\
\hline
\end{tabular}

Table 4: The loess sample permeability test data.

\begin{tabular}{lccccc}
\hline Sample number & & Dry density $\left(\mathrm{g} \cdot \mathrm{cm}^{-3}\right)$ & Void ratio & Initial water content $(\%)$ & Permeability coefficient $\left(\times 10^{-5} \mathrm{~cm} / \mathrm{s}\right)$ \\
\hline & 1 & 1.35 & 1.007 & 9.9 & 2.660 \\
& 2 & 1.35 & 1.007 & 9.9 & 1.689 \\
Water permeability & 3 & 1.36 & 0.993 & 9.9 & 2.241 \\
& 4 & 1.35 & 1.007 & 9.9 & 1.179 \\
& 5 & 1.34 & 1.022 & 9.9 & 1.516 \\
\hline Air permeability & 6 & 1.25 & 1.168 & 8.7 & $100 \sim 4500$ (influenced by water content: around \\
{$[14]$} & \multirow{2}{*}{$1.28 \sim 1.39$} & $0.95 \sim 1.10$ & $7.67 \sim 15.20$ & $2000 \sim 3000$ at the water content of $10 \%)$ \\
\hline
\end{tabular}


TABLE 5: Correlation coefficients between laboratory data of external loading (EL), residual deformation (RD), and pore pressure (PP).

\begin{tabular}{|c|c|c|c|c|c|}
\hline \multirow{2}{*}{ Sample number/testing type } & \multicolumn{3}{|c|}{ Correlation coefficient } & \multirow{2}{*}{\multicolumn{2}{|c|}{ Remark }} \\
\hline & EL-RD & EL-PP & RD-PP & & \\
\hline \multirow{4}{*}{$1 / \mathrm{US}$} & 0.6021 & 0.2154 & -0.6103 & & rocess \\
\hline & 0.9780 & 0.9657 & 0.9416 & No. 1 & \multirow{3}{*}{ Single stage } \\
\hline & 0.9521 & 0.6426 & 0.7682 & No. 2 & \\
\hline & 0.8346 & -0.7284 & -0.9751 & No. 3 & \\
\hline \multirow{5}{*}{$4 / \mathrm{SS}$} & 0.5601 & 0.7480 & 0.9421 & \multicolumn{2}{|c|}{ Response process } \\
\hline & 0.9620 & 0.9343 & 0.9923 & No. 1 & \multirow{4}{*}{ Single stage } \\
\hline & 0.9815 & 0.9431 & 0.9987 & No. 2 & \\
\hline & 0.9645 & 0.9698 & 0.9965 & No. 3 & \\
\hline & -0.8623 & -0.8092 & 0.9634 & No. 4 & \\
\hline \multirow{4}{*}{$7 / \mathrm{SD}$} & -0.0316 & -0.0598 & 0.7257 & \multicolumn{2}{|c|}{ Response process } \\
\hline & 0.2256 & -0.0024 & 0.9454 & No. 1 & \multirow{3}{*}{ Single stage } \\
\hline & 0.0745 & 0.0147 & 0.9365 & No. 2 & \\
\hline & 0.0082 & -0.0059 & 0.7973 & No. 3 & \\
\hline \multirow{4}{*}{ 9/UD } & 0.8160 & 0.4555 & 0.8355 & \multicolumn{2}{|c|}{ Response process } \\
\hline & 0.9854 & 0.5971 & 0.6199 & No. 1 & \multirow{3}{*}{ Single stage } \\
\hline & 0.9415 & 0.7165 & 0.8313 & No. 2 & \\
\hline & 0.9424 & 0.7308 & 0.8436 & No. 3 & \\
\hline \multirow{2}{*}{ Average value of all stages } & 0.7471 & 0.6200 & 0.8930 & \multirow{2}{*}{\multicolumn{2}{|c|}{$\begin{array}{l}\text { Absolute value } \\
\text { Value }\end{array}$}} \\
\hline & 0.6145 & 0.3822 & 0.7430 & & \\
\hline
\end{tabular}
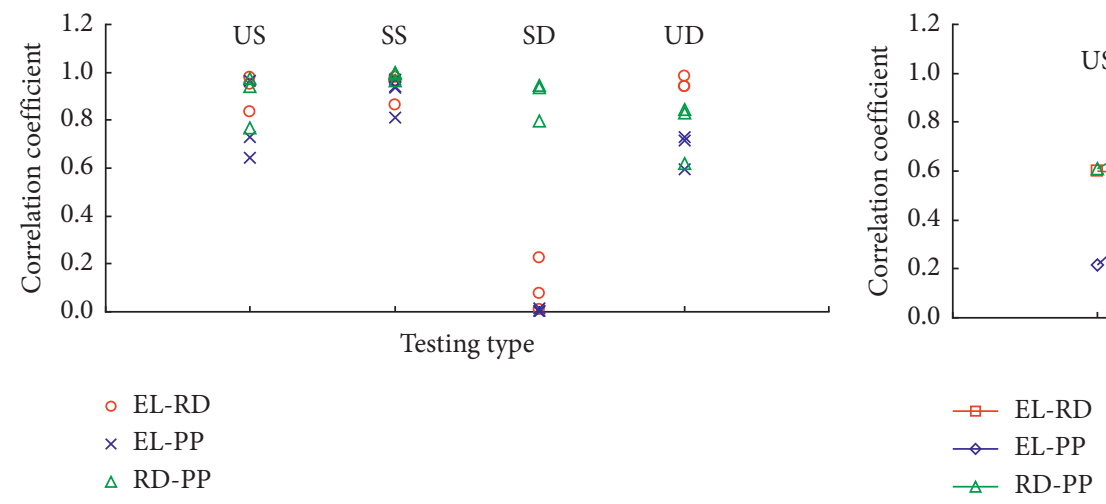

(a)

(b)

FIGURE 5: Correlations between external loading, residual deformation, and pore pressure (US/UD: air pressure; SS/SD: water pressure). (a) Different stages. (b) Response process.

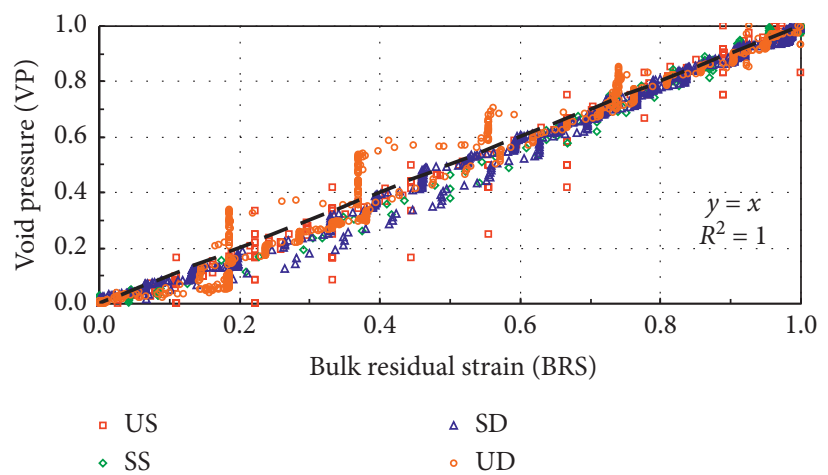

(a)

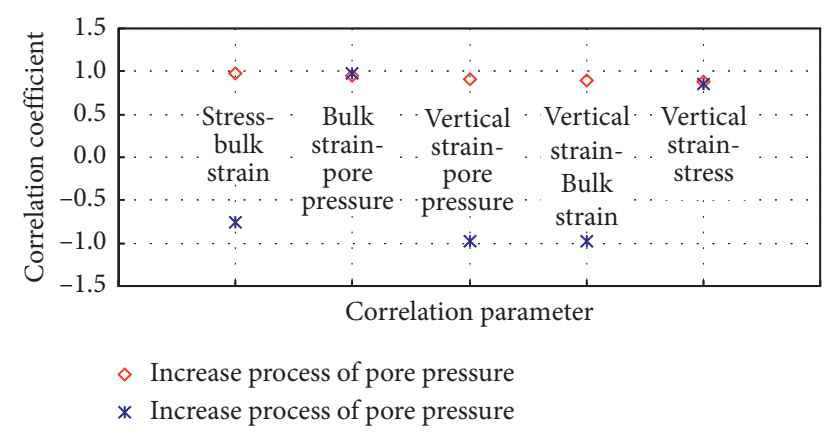

(b)

FiguRE 6: The same responding process of void air/water pressures under bulk residual strain and their controlling relation analysis. (a) Identical response process (samples 1-10). (b) Controlling relation analysis (sample 1). 
have to be based on the response ability of solid phase medium to load stress. All of these verify the direct passivity of solid phase medium and the indirect passivity of water/air phase medium.

\subsection{Different Developing Values of Pore Water and Air} Pressures. Figure 7 shows the analysis results about the difference of void water/air pressure response. The consistency of void water/air pressure in the process of external load could not be influenced by the original stress and load stress condition and the physical characteristics of water/air phase medium, but the different physical properties of water and air phase media should lead to the obvious difference of pore water/air pressure in absolute response value.

Ishihara and Yasuda [15] verified the decisive effect of confining pressure on the pore water pressure final value by the liquefaction test of CM and EM. From Table 1 we can know that the confining pressure of samples 1 to 3 and 9 to 10 is in the range from 50 to $150 \mathrm{kPa}$. The results in Figure 7(a) show that the soil pore air pressure does not have obvious dependence to confining pressure in the process of dynamic/static load. On the contrary, in terms of pore water pressure, the influence of confining pressure is obvious (see Figure 7(b)). The confining pressure of samples 4 to 6 is 50, 100 , and $150 \mathrm{kPa}$, and the confining pressure of samples 7 to 8 is $90 \mathrm{kPa}$. Figure 7(b) shows that the pore water pressure value of samples 4 to 6 is close to the confining pressure; at the same time, the pore water pressure of sample 5 and samples 7 to 8 which have similar confining pressure has better correlation. Wang et al. found that the apparent viscosity will reduce with the increase of shear strain rate tested by rate dependence of viscosity [16]. So, we can judge that the unsaturated loess has a higher strength and the pore air pressure only has relation with bulk residual strain after load. The pore water pressure of saturated loess with lower strength and higher deformability is related not only to bulk residual strain but also to confining pressure which can transfer the pressure of soil particles structure to pore water more effectively. Of course, the conclusion of the correlation between pore water/air pressure and confining pressure should also have relationship with the physical characteristics of water/air phase medium, namely, the higher compressibility may reduce the effect of confining pressure on the pore air pressure.

The soil bulk residual strain has obvious difference in the control effect of pore air/water pressure absolute value. Figure 7 shows that the effect of bulk residual strain on the pore water pressure is about 10 times the void air pressure (22.708/2.2663). The control effect of bulk residual strain of soil on the pore air/water pressure in the actual site soil is produced by the comprehensive effect of the permeability and compressibility of water/air phase medium. In fact, the permeability of water and air phase medium in soil determined the solid phase medium compression effect of these phases, namely, the control effect of pore water/air pressure values. Because the conditions of the static/dynamic triaxial test in the paper are no drainage and no exhaust, the effect difference should mainly have relation with some inherent properties such as compressibility of water/air phase medium and compression effect of solid phase medium on other phases. In addition, Table 1 shows the saturation of samples 4 to 8 are in the range from $81 \%$ to $93 \%$, which are not saturated completely in the saturation test (the saturation test being a big problem for the natural loess needing to keep the original structure [13]). This fact may be the reason why the samples can produce the measurable bulk residual strain and may have effect on the ratio of the pore air/water pressure effect. Because of the nearly incompressibility of water and solid particles, it is difficult for the saturated loess to produce measurable bulk residual strain in the triaxial test without drainage, but the solid particles have potential compression stress on the water phase medium. These should be the determining factors to the development of pore water pressure. When the soil is completely saturated, the difference of response pressure between pore water and air may be more than 10 times.

3.4. Controlling Residual Deformation on Pore Pressure. As shown in Figure 3, the laboratory data are clear to describe the response features of pore pressure of water and air, vertical residual strain, and bulk residual strain. For understanding the controlling relationship between residual deformation and pore pressure well, we get Figure 8 based on the data in Figure 4.

Nagase et al. revealed that the development of pore pressure has relation with vertical loading, and the pressure becomes greater with the loading of shear stress [17]. Figure 8 shows a similar result. The vertical residual strain has a clear relation with bulk residual strain and pore pressure, although it is nonlinear. All laboratory data of 10 samples develop exponentially, except two samples of 1 and 9. For the samples of 2-8 and 10, the goodness of fit reaches above 0.90 ; the goodness of fit of sample No. 9 is around 0.70 .

Cai and $\mathrm{Wu}$ reported that the development of crack could provide dominant passages for the dissipation of exceeding pore pressure [18]. During the triaxial testing, sample 1 suffers a shear failure (see Figure 9). For sample 1, the relations between vertical residual strain and bulk residual strain obviously differ from other samples' results, as well as the relation of pore air pressure and vertical residual strain (see Figures 8(a) and 8(b)). After there is a shear plane across the loess sample, the residual deformation should not have a relation with external loadings. Then, the residual deformation of soil would be controlled by the shear plane due to the fact that the solid particle structure could not effectively respond to external loadings. As shown in Figures $8(\mathrm{a})$ and $8(\mathrm{~b})$, the decrease of pore air pressure only discloses one fact that there is no effective loading to enhance the air pressure. By this method, the controlling effects of residual deformation on pore pressure can be obtained. Figures $8(\mathrm{a})$ and $8(\mathrm{~b})$ distinctly describe the controlling process. Before the shear failure occurs, the pore pressure increases due to the effective loading of solid media on the two phases of water and air. During this stage, the increment of pore pressure is much greater than other samples. After the shear failure occurs, the pore pressure continually 


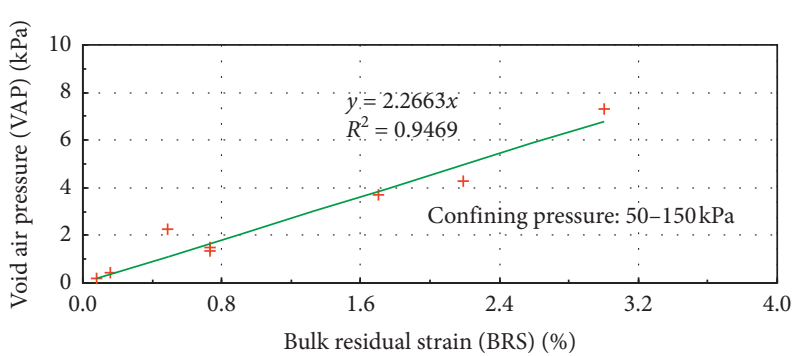

(a)

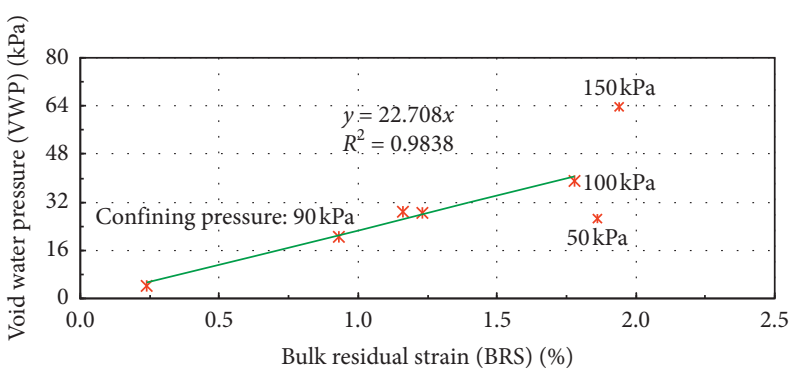

(b)

Figure 7: Controlling influence of bulk residual strain on void air/water pressures (based on the maximum values in Table 2). (a) Independent of confining pressure (samples 1-3 and 9-10). (b) Dependent of confining pressure (samples 4-8).

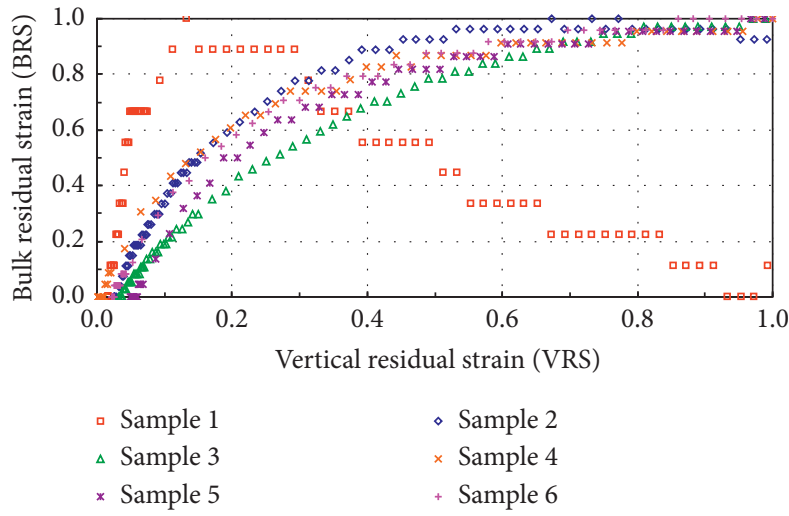

(a)

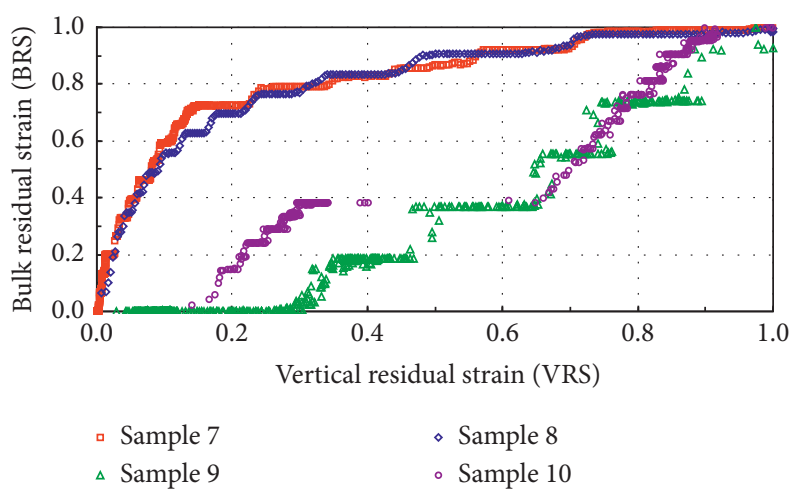

(c)

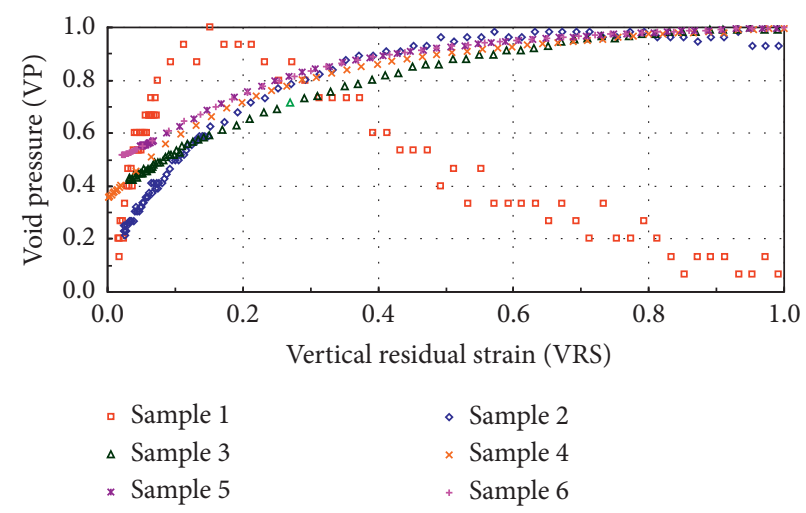

(b)

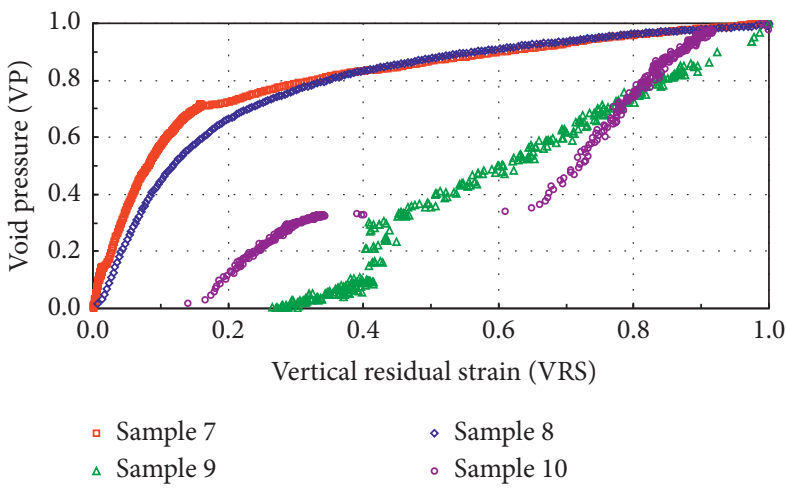

(d)

FIGURE 8: Relationship between vertical residual strain, bulk residual strain, and void pressure (the same normalized method as shown in Figure 2). (a) Samples 1-6 (US/SS). (b) Samples 1-6 (US/SS). (c) Samples 7-10 (SD/UD). (d) Samples 7-10 (SD/UD).

decreases due to the fact that there is no effective force resource. Compared with vertical residual strain, the response features of bulk residual strain and pore pressure should have two different kinds of features due to shear failure. The obvious difference between the two kinds of response features is the increment characteristics of bulk residual strain and pore pressure. In case of the appearance of shear failure, the developing value of pore pressure would continually decrease to 0 after the failure occurs, but for that no occurrence of shear failure, the pore pressure should reach up to an extreme.
Compared to the developing process of vertical residual strain, as shown in Figures 8(c) and 8(d), the bulk residual strain and pore pressure have an obvious difference between saturated and unsaturated loess under dynamic loadings. From Table 2, the absolute value of pore air pressure obviously differs from pore water pressure, as well as the response time history. Compared with the response of pore water pressure of saturated loess samples, the difference of pore air pressure between different unsaturated loess samples is more obvious. The results of Figures $8(\mathrm{a})$ and $8(\mathrm{~b})$ show that the response processes of pore water and air 


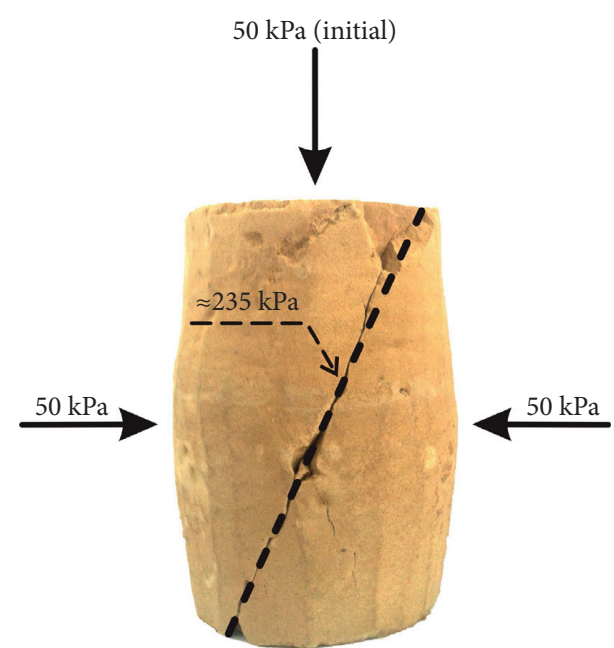

FIGURE 9: Shear failure within loess sample 1 (US).

pressure of saturated and unsaturated loess are all same, which indicates that the static loading has better control effect than the dynamic loading. In one word, under the both uncertainty of dynamic stress and air medium, residual strain and pore air pressure should have a more complicated response characteristic.

In summary, if we apply vertical residual strain to study the response characteristics, we could find out it has a few blind areas, such as the difference between shear failure and nonshear failure under static loadings and between saturated and unsaturated loess under dynamic loading. This result means that it is difficult to uniformly describe the two kinds of different response processes of pore pressures by means of vertical residual strain. However, the bulk residual strain has a similar response process with pore pressure. For determining the quantitative relationship between the bulk residual strain and pore pressure, we can get Figure 10 resulting from Figure 9.

Compared with the axial residual strain, the response process of bulk residual strain has a better correspondence with pore air or water pressure (see Figures 8 and 10). Meanwhile, the dispersion degree of pore air pressure is higher than pore water pressure, which is consistent with the analysis results in Figure 10. Figures 10(b) and 10(d) show that the bulk residual strain always has a clear relation with the pore water pressure of loess soils under static/dynamic loadings. For the response process of pore air pressure, the dispersion characteristics of static and dynamic loadings are different. The static loading tends to a lower response value, whereas the dynamic loading has a higher value (see Figures 10(a) and 10(d)). These differences between pore air and water pressures under static and dynamic loadings may be caused by the different loading effects of static and dynamic loadings on loess soils. However, the real physical meaning of the difference needs to be studied by further research works.

\section{Discussion}

It is the essential problem of unified dynamic mechanism of seismic subsidence and liquefaction to understand the real role of solid particle structure during the response process of loess soil under external loadings. Water, gas, and other fluids have no fixed form, which is related to their ability to withstand shearing action. If the fluid needs to take additional pressure, an external constraint, known as container, should be required. For the soil triphase of solid, water, and air, the solid phase has obvious difference with other phases. Water and air fill in the pore of the solid particle structure, so solid phase can be treated as a container, maintaining water phase and air phase. It inevitably leads to the fact that the solid phase must be loaded at first when the external static/ dynamic loads are applied. When the relative space position of solid phase (soil particle) has been changed (for typical natural loess, generally being volume compression), water phase and air phase could suffer the secondary response to the soil residual deformation.

The mechanism consistency of the solid phase medium influencing the air/water phase medium determines the response process of pore pressure under loadings which has no substantial difference. The inherent properties of water and air phase medium determine the pore pressure absolute value under special conditions of original stress and loading stress. When the soil in field is loaded, the absolute value of pore pressure has close relation with the permeability and compressibility of water and air phase medium, and the permeability directly decides the compression effect of solid particles on the air/water phase medium. In the case of no drainage and no exhaust conditions of the laboratory triaxial test, the compression effect is due to the compression of water/air phase medium and the saturation degree of samples.

The vertical residual strain of soil with or without shear failure under static loading cannot uniformly describe the pore air pressure. Under the dynamic load, the vertical residual strain also cannot uniformly describe the void air/ water pressure. But all of them can be generated by the soil bulk residual strain. This phenomenon indicates that the process of producing void air/water pressure and the cause of the load response of soil is consistent no matter what the load mode is. The variability of void air pressure of unsaturated loess is greater than the void water pressure of saturated loess, which is influenced by the difference of water/air phase medium physical properties (permeability and compressibility). For the absolute value, the water effect on void water pressure is higher than the air effect on void air pressure about 1 order of magnitude. At the same time, the void water pressure has high dependence to confining pressure which is opposite to the void air pressure.

The residual deformation of solid phase skeleton and the low permeability of water/air phase medium are the determining factors to induce the increase of pore pressure. The residual deformation has controlling effect on pore pressure; in terms of saturated loess, the controlling effect of residual deformation will reduce obviously when the pore pressure is close to confining pressure, which reflects the different controlling sequence of load stress to residual deformation and pore pressure. The test phenomenon involved in these conclusions and the direct response of solid phase medium relative to other phases should be the 


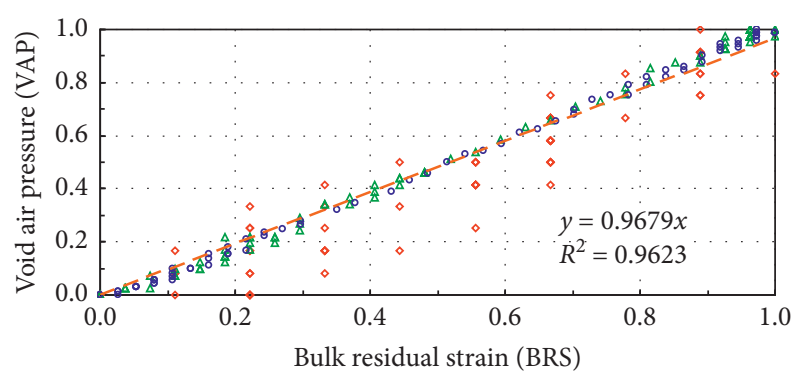

- Sample 1

$\triangle$ Sample 2

- Sample 3

(a)

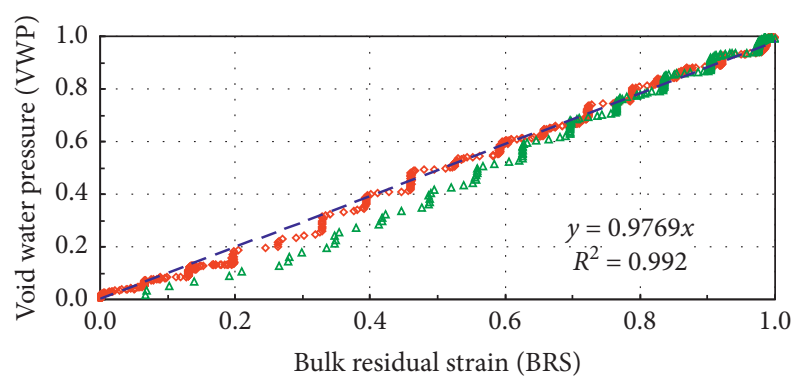

- Sample 7

$\triangle$ Sample 8

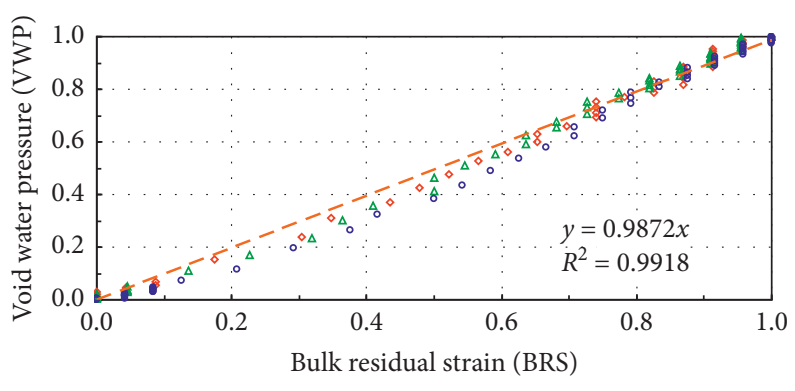

- Sample 4

$\triangle$ Sample 5

- Sample 6

(b)

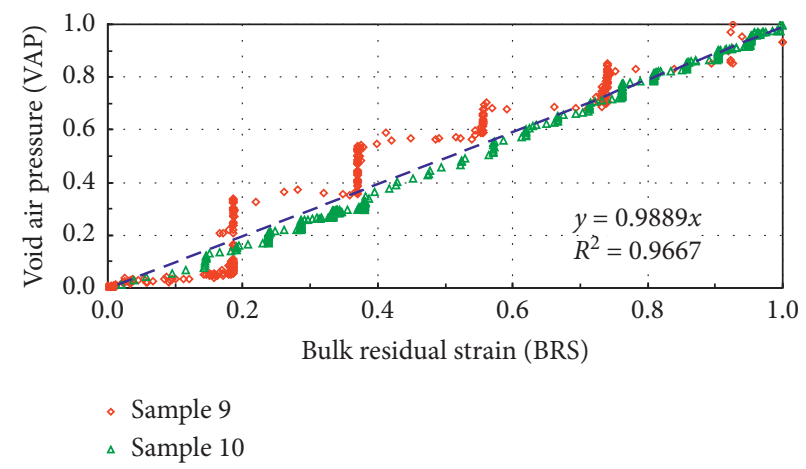

(d)

(c)

FIGURE 10: Relationship between bulk residual strain and void pressure (the same normalized method as shown in Figure 2). (a) Samples 1-3 (US). (b) Samples 4-6 (SS). (c) Samples 7-8 (SD). (d) Samples 9-10 (UD).

evidence to verify the causality between residual deformation and pore pressure.

To analyse the correlation of test data among load stress, residual deformation and pore pressure could make the relationship clear among them. In the inherent form, the solid, water, and air phase media have difference when they respond to the external load, and this difference has close relation with the existence property of water/air phase medium filled in the void structures made of solid phase medium. Whether the soil is saturated or unsaturated, the solid phase skeleton is the main media to transfer the external load to the soil, and the response of water/air phase medium on the load is controlled by residual deformation of soil particle structure. This means that compared with the direct response of solid phase medium to the load, water/air phase medium has obviously indirect response properties.

The unsaturated loess dynamic residual deformation and saturated loess liquefaction have obvious difference in the macrophenomenon, but both of them have consistency in the mechanical mechanism. In short, the unity dynamic response mechanism of unsaturated and saturated loess can be summarized as follows: when the strength of soil is greater than the original dynamic stress of dynamic load, the solid phase produces residual deformation and leads to the compression of water/air phase medium and the increase of pore pressure; because of the obvious difference of water/air phase medium permeability and compressibility, the phenomenon results (earthquake subsidence and liquefaction) are also different. This result may have reference significance to describe the complex physical process of saturated/unsaturated loess dynamic response from the view of unity.

\section{Conclusions}

For the loess soil, the two phases of water and air fill in the skeleton structure made of solid particles. When the external load acts on the soil, the solid phase will be the first-response media on this load. Then, the previous volume also suffers a change, which could make water and air to develop a pressure. In this process, the response property of the solid phase medium is direct passivity, whereas the response properties of other two phases are indirect passivity.

The loading stress makes the solid particle structure generate residual deformation, and water and air phase media lead to the change of pore pressure in the indirect loading process. Therefore, there has been correlation among loading stress, residual deformation, and pore pressure. The test and data results as well as theory analysis have already verified the fact that residual deformation controls pore pressure.

The loading form of external loads could influence the real loading effect on soil, but the disturbance on the soil has no difference. This kind of disturbance should control the distribution of solid particles at a certain stress condition. Since pore water pressure and pore air pressure are caused by volume change under external load, they have consistency 
in the cause. However, the physical property difference of air phase and water phase like permeability and compressibility makes the absolute values of void water and air pressures express an obvious difference.

Although seismic subsidence and liquefaction are obviously different, they have the same dynamic response mechanism. In one word, the process that external loads acts on the soil causes two different dynamic behaviors loess, seismic subsidence and liquefaction. The residual deformation of the solid phase makes the water and air phase responding to external loads and then generating pore water and air pressure. The difference between them has relations with the different physical properties of water and air phase media such as permeability and compressibility.

\section{Data Availability}

The data used to support the findings of this study are available from the corresponding author upon request.

\section{Conflicts of Interest}

The authors declare that there are no conflicts of interest regarding the publication of this paper.

\section{Acknowledgments}

This study was supported by the Fundamental Research Funds for the Institute of Earthquake Forecasting, China Earthquake Administration (no. 2019IESLZ04), and $\mathrm{Na}$ tional Natural Science Foundation of China (no. 51779234). The authors would like to thank Dr. Shunhua Xu for his kind help in field survey and Dr Qian Wang and Mr. Minjie Feng for their help in laboratory tests.

\section{References}

[1] G. R. Gao, "The loess microscopic structure and collapsibility," Science in China, vol. 23, no. 12, pp. 1203-1208, 1980.

[2] X. Y. Lei, "The loess collapsibility and pore types in China," Scientia Sinica (Chimica), vol. 12, no. 12, pp. 1309-1318, 1987.

[3] T. D. Miao, Z. Y. Liu, and J. S. Ren, "Deformation mechanism and constitutive relation of collapsible loess," Chinese Journal of Geotechnical Engineering, vol. 21, no. 4, pp. 783-787, 1999.

[4] C. D. F. Rogers, T. A. Dijkstra, and I. J. Smalley, "Hydroconsolidation and subsidence of loess: studies from China, Russia, North America and Europe," Engineering Geology, vol. 37, no. 2, pp. 83-113, 1994.

[5] H. B. Seed and C. K. Chan, "Clay strength under earthquake loading condition," Journal of the Soil Mechanics and Foundations Division, ASCE, vol. 92, no. 2, pp. 53-78, 1966.

[6] K. L. Lee, Seismic Permanent Deformation in and Applied Science, Mechanics and Structures Department, School of Engineering, Los Angeles, CA, USA, 1974.

[7] H. B. Seed and I. M. Idriss, "Simplified Procedure for evaluating soil liquefaction potential," Soil Mechanics and Foundations Division, ASCE, vol. 97, no. 9, pp. 1249-1273, 1971.

[8] L. M. Wang and J. J. Sun, "Seismic safety issues in the process of urban development in Loess Plateau," Earthquake Engineering and Engineering Dynamics, vol. 34, no. 4, pp. 115-122, 2014.
[9] C. S. Chang, "Residual undrained deformation from cyclic loading," Journal of the Geotechnical Engineering Division, ASCE, vol. 108, no. 4, pp. 637-646, 1982.

[10] T. Kimura and K. Saitoh, "The influence of strain rate on pore pressures in consolidated undrained triaxial tests on cohesive soils," Soils and Foundations, vol. 23, no. 1, pp. 80-90, 1983.

[11] H. Yamaguchi, Y. Ohira, K. Kogure, and S. Mori, "Undrained shear characteristics of normally consolidated peat under triaxial compression and extension conditions," Soils and Foundations, vol. 25, no. 3, pp. 1-18, 1985.

[12] Z. J. Shi, "Variation law of void water pressure of saturated sand under cyclic loading controlled by constant amplitude strain," World Information on Earthquake Engineering, vol. 3, no. 3, pp. 49-53, 1987.

[13] L. M. Wang, Y. C. Shi, X. Liu et al., Loess Dynamics, Earthquake Press, Beijing, China, 2003.

[14] Z. H. Yao, Z. H. Chen, X. F. Huang et al., "Experimental research on gas permeability of unsaturated Q3 loess," Chinese Journal of Rock Mechanics and Engineering, vol. 31, no. 6, pp. 1264-1273, 2012.

[15] K. Ishihara and S. Yasuda, "Sand liquefaction under random earthquake loading condition," in Proceedings of the 5th WCEE, pp. 329-338, Ministry of Public Works, Rome, Italy, June 1973.

[16] Z. H. Wang, E. Q. Zhou, and G. X. Chen, "Fluid characteristics dependent on excess pore water pressure of saturated sand after growth of pore pressure," Chinese Journal of Geotechnical Engineering, vol. 34, no. 3, pp. 528-533, 2012.

[17] H. Nagase and K. Ishihara, "Effects of load irregularity on the cyclic behaviour of sand," Soil Dynamics and Earthquake Engineering, vol. 6, no. 4, pp. 239-249, 1987.

[18] Q. P. Cai and H. W. Wu, "Deformation mechanism and variation of pore pressure due to normal fault propagation in cemented clay," Chinese Journal of Rock Mechanics and Engineering, vol. 33, no. 2, pp. 390-395, 2014. 